\title{
Trends in the incidence of AIDS-defining and non-AIDS-defining cancers in people living with AIDS: a population-based study from São Paulo, Brazil
}

International Journal of STD \& AIDS 2017, Vol. 28(I2) 1190-1198 (C) The Author(s) 2017 Reprints and permissions: sagepub.co.uk/journalsPermissions.nav DOI: $10.1177 / 0956462417692924$ journals.sagepub.com/home/std SSAGE

\author{
Luana F Tanaka ${ }^{1,2,3}$, Maria do Rosário DO Latorre ${ }^{2,3}$, \\ Eliana B Gutierrez ${ }^{4}$, Christian Heumann ${ }^{5}$, Karl-Heinz Herbinger 6 \\ and Guenter Froeschl ${ }^{1,6}$
}

\begin{abstract}
People living with AIDS are at increased risk of developing certain cancers. Since the introduction of the highly active antiretroviral therapy (HAART), the incidence of AIDS-defining cancers (ADCs) has decreased in high-income countries. The objective of this study was to analyse trends in ADCs and non-AIDS-defining cancers (NADCs) in HIV-positive people with a diagnosis of AIDS, in comparison to the general population, in São Paulo, Brazil. A probabilistic record linkage between the 'Population-based Cancer Registry of São Paulo' and the AIDS notification database (SINAN) was conducted. Cancer trends were assessed by annual per cent change (APC). In people with AIDS, 2074 cancers were diagnosed. Among men with AIDS, the most frequent cancer was Kaposi's sarcoma (469; 3I.I\%), followed by nonHodgkin lymphoma (NHL; 304; 20.1\%). A decline was seen for ADCs (APC=-14.1\%). All NADCs have increased $(A P C=7.4 \% / y e a r)$ significantly since the mid-2000s driven by the significant upward trends of anal $(A P C=24.6 \% / y e a r)$ and lung cancers (APC $=15.9 \% / y e a r)$. In contrast, in men from the general population, decreasing trends were observed for these cancers. For women with AIDS, the most frequent cancer was cervical (II4; 20.2\%), followed by NHL (96; 17.0\%). Significant declining trends were seen for both ADCs (APC $=-15.6 \% /$ year) and all NADCs (APC $=-15.8 \% /$ year), a comparable pattern to that found for the general female population. Trends in cancers among people with AIDS in São Paulo showed similar patterns to those found in developed countries. Although ADCs have significantly decreased, probably due to the introduction of HAART, NADCs in men have shown an opposite upward trend.
\end{abstract}

\author{
Keywords \\ South America, epidemiology, AIDS, HPV, HIV, cancer
}

Date received: 8 August 2016; accepted: 10 January 2017

\section{Introduction}

Several studies have shown an increased risk for cancer among people living with HIV/AIDS (PLWHA); however, the risks have changed over time. Since the introduction of the highly active antiretroviral therapy (HAART), some countries have documented significant declines in AIDS-defining cancers (ADCs), namely Kaposi's sarcoma (KS), non-Hodgkin lymphoma (NHL) and cervical cancer (CC). In contrast to this, increasing trends in non-AIDS-defining cancers (NADCs) were found in many recent studies. ${ }^{1-5}$ Most of the studies assessing cancer burden in PLWHA have been conducted in developed countries, such as the United States (US), Spain and Italy, where population-based
'Center for International Health, Medical Center of the University of Munich (LMU), Munich, Germany

${ }^{2}$ Department of Epidemiology, School of Public Health, University of São Paulo, São Paulo, Brazil

${ }^{3}$ Population-Based Cancer Registry of São Paulo, Department of Epidemiology, School of Public Health, University of São Paulo, São Paulo, Brazil

${ }^{4}$ Programa Municipal DST-AIDS, Secretaria Municipal de Saúde, São Paulo, Brazil

${ }^{5}$ Institute of Statistics, University of Munich (LMU), Munich, Germany ${ }^{6}$ Division of Infectious Diseases and Tropical Medicine, Medical Center of the University of Munich (LMU), Munich, Germany

Corresponding author:

Luana F Tanaka, Avenida Dr Arnaldo, 7 I 5 São Paulo-SP 01246-904, Brazil. Email: luanaft@usp.br 
cancer and AIDS registries coexist. Unfortunately, in many countries, both at high- and or middle-income levels, such studies are not feasible, due to the lack of population-based registries, or due to the inability of conducting record linkage because of anonymized records, poor database quality or intermittent data collection, among other constraints.

In Brazil, AIDS notification became mandatory in 1986 and cases diagnosed before that time were recorded retrospectively. The state of São Paulo has played a crucial role in the AIDS epidemic, having launched the first AIDS programme in the country, providing treatment free of cost. ${ }^{6}$ São Paulo city has the highest percentage $(12.6 \%)$ of all AIDS cases diagnosed nationally. ${ }^{7}$ The city also has a population-based cancer registry, which covers the largest population in Brazil, and has uninterruptedly collected data on cancer incidence since 1997.

The present study analysed the trends in incidence of cancers in residents of São Paulo with HIV between 1997 and 2012, in comparison to the general population.

\section{Methods}

A total of 87,109 AIDS cases were diagnosed in HIVpositive persons aged $\geq 13$ years in São Paulo from 1980 to 2013. ${ }^{8}$ Between 1997 and 2012, the 'Population-based Cancer Registry of São Paulo' (PBCR-SP) registered 628,161 cancers (496,276 invasive) among São Paulo residents.

A probabilistic record linkage was conducted between the PBCR-SP (1997-2012) and the AIDS notification database SINAN (Sistema de Informações de Agravos de Notificação/Information System on Disease Notification) (1980-2013) containing AIDS cases. The Brazilian Ministry of Health preferably uses the AIDS case definition of the Centers for Disease Control and Prevention and alternatively the definition of Rio de Janeiro/Caracas. ${ }^{9}$ Both registries cover the same territory: the city of São Paulo, which according to the 2010 census, comprises an area of $1521 \mathrm{~km}^{2}$ and is home to $11,253,503$ inhabitants $(99.1 \%$ urban), corresponding to almost $6 \%$ of the Brazilian population. Its current human development index is $0.805 .{ }^{10}$

A probabilistic record linkage was conducted, in a multi-step process, using different blocking strategies. Soundex, which is the phonetic algorithm for indexing names by sound, was used in place of names for blocking. The blocking strategies contained a combination of soundex of the first name, soundex of the last name, decade of birth and sex. Full name and date of birth were used for calculating the weighted scores. Clerical review based on name, date of birth, mother's name and address, when available, was carried out in all steps to improve record linkage sensitivity. This process was conducted using the open source software OpenRecLink (version 2.9). After the identification of true matches, patients were excluded from the analysis if they had a cancer diagnosis 60 months or more prior to their AIDS diagnosis.

Cancers were grouped into two major categories: ADCs (KS, NHL and CC) and NADCs (all other cancers). The annual AIDS population according to gender and age group was estimated as the difference between cumulative cases and cumulative deaths per year.

The crude incidence rates were calculated according to gender, dividing the number of incident cases by the estimated AIDS population in a given year and presented as rates per 100,000 persons. Crude rates were also calculated according to the following age groups: 20-29, 30-39, $40-49,50-59,60-69$ years. As for the general population, the denominator for rates was the resident population of São Paulo, as provided by the Brazilian Institute of Geography and Statistics. ${ }^{10}$ Age-standardized rates (ASRs) by sex were calculated using the direct method based on the world population, as proposed by SEGI and modified by Doll and Waterhouse. ${ }^{11}$

In the descriptive analyses, persons with multiple cancer diagnoses were only included once (considering the first cancer). To assess trends in ADCs, NADCs and most incident cancers (anal, colorectal and lung cancers in men; breast and colorectal cancers in women) in the population with AIDS, the three-year moving average of the ASR was calculated. Subsequently, the annual per cent change (APC) was estimated, as follows: $\mathrm{APC}=\left[\exp \left(\beta_{\text {year }}\right)-1\right] \times 100$, and its respective $95 \%$ confidence intervals with exponentially transformed values using the Joinpoint software (version 4.2.0.2). Data from the PBCR-SP were analysed to assess trends in cancer incidence in the general population. The series of the PBCR-SP started in 1997. Since its trends are greatly affected by the AIDS epidemic, no specific trend analysis for the general population was conducted for KS.

To compare risk for cancer within age groups, the ratio between crude age-specific rates of the oldest age group (60-69 years) and the youngest (20-29 years) was calculated. All statistical analyses were stratified by sex.

This research obtained ethical clearance from the Ethics Review Board at the School Public Health, University of São Paulo (686.849), from the Municipal Health Secretariat of São Paulo (703.467) and from the University of Munich (233.15). After record linkage, the database was anonymized to ensure data privacy.

\section{Results}

Table 1 displays the main characteristics of all AIDS cases registered in São Paulo from 1980 to 2013. 
Table I. Socio-demographic characteristics of people diagnosed with AIDS, according to gender. São Paulo, 1980-2013.

\begin{tabular}{|c|c|c|c|c|c|c|}
\hline & \multicolumn{2}{|l|}{ Total } & \multicolumn{2}{|l|}{ Male } & \multicolumn{2}{|l|}{ Female } \\
\hline & $\mathrm{n}$ & $\%$ & $\mathrm{n}$ & $\%$ & $\mathrm{n}$ & $\%$ \\
\hline \multicolumn{7}{|l|}{ Race/ethnicity } \\
\hline White & 21,935 & 25.2 & 15,360 & 24.2 & 6575 & 27.8 \\
\hline Black & 4292 & 4.9 & 2715 & 4.3 & 1577 & 6.7 \\
\hline Asian & 303 & 0.3 & 214 & 0.3 & 89 & 0. \\
\hline Pardo $^{\mathrm{a}}$ & 10,079 & 11.6 & 6484 & 10.2 & 3595 & 15.2 \\
\hline Indigenous & 64 & 0.1 & 48 & 0.1 & 16 & 0.1 \\
\hline Unknown & 50,436 & 57.9 & 38,616 & 60.9 & 11,820 & 49.9 \\
\hline \multicolumn{7}{|c|}{ Age at AIDS diagnosis (years) } \\
\hline $13-19$ & 1453 & 1.7 & 963 & 1.5 & 490 & 2.1 \\
\hline $20-29$ & 22,818 & 26.2 & 16,044 & 25.3 & 6774 & 28.6 \\
\hline $30-39$ & 34,892 & 40.1 & 26,132 & 41.2 & 8760 & 37.0 \\
\hline $40-49$ & 18,944 & 21.7 & 13,964 & 22.0 & 4980 & 21.0 \\
\hline $50-59$ & 6548 & 7.5 & 4621 & 7.3 & 1927 & 8.1 \\
\hline $60-69$ & 1853 & 2.1 & 1258 & 2.0 & 595 & 2.5 \\
\hline$\geq 70$ & 423 & 0.5 & 311 & 0.5 & 112 & 0.5 \\
\hline Unknown & 178 & 0.2 & 144 & 0.2 & 34 & 0. \\
\hline \multicolumn{7}{|l|}{ HIV exposure category } \\
\hline Homosexual men & 17,589 & 20.2 & 17,589 & 27.7 & NA & NA \\
\hline Bisexual & 6001 & 6.9 & 5977 & 9.4 & 24 & 0.1 \\
\hline Heterosexual & 31,550 & 36.2 & 14,832 & 23.4 & 16,718 & 70.6 \\
\hline Intravenous drug user & 13,643 & 15.7 & II,256 & 17.7 & 2387 & 10.1 \\
\hline Other & 595 & 0.7 & 402 & 0.6 & 193 & 0.8 \\
\hline Unknown & $|7,73|$ & 20.4 & $|3,38|$ & 21.1 & 4350 & 18.4 \\
\hline Total & 87,109 & 100 & 63,437 & 100 & 23,672 & 100 \\
\hline
\end{tabular}

NA: not applicable.

${ }^{\text {a }}$ ardo refers to multiracial persons of African ancestry.

Source: Epidemiological surveillance on STDs/AIDS, Municipal Department of Health, São Paulo, Brazil.

The majority of cases were men (72.8\%), aged 20-49 years $(88.5 \%)$ at AIDS diagnosis. The estimated number of persons living with AIDS increased substantially from 13,895 (of which $76.1 \%$ are males) in 1997 to 44,741 (of which $69.0 \%$ are males) in 2012 . Young males (20-49 years) accounted for over $60 \%$ of the AIDS population at risk of cancer (data not shown).

Of all 496,276 invasive cancers diagnosed between 1997 and 2012, 2074 cancers occurred in 2000 persons with AIDS. Seventy-four persons were diagnosed with two primary site tumours, thus, the descriptive statistics shown in Table 2 was based on 2000 persons. The majority were male $(1461 ; 73.0 \%)$, white (1111; $55.6 \%)$ and aged $30-49$ years old at cancer diagnosis $(1257 ; 62.9 \%)$. Heterosexual $(674 ; 33.7 \%)$ and homosexual $(447 ; 22.4 \%)$ practices were the most frequent stated categories of exposure to HIV.

Table 3 presents the number of cases and trend analyses of ADCs, NADCs, and most incident cancers in men and women both with AIDS and from the general population; in these analyses all 2074 cancers were considered. Most cancers $(51.0 \%$; 1057 out of 2074 cancers) in the AIDS population were classified as NADCs, corresponding to $56.7 \%$ cancers in women $(\mathrm{n}=320)$. In men, ADCs were slightly more frequent than NADCs, representing $51.2 \%(\mathrm{n}=773)$ of all 1510 male cases. The five most incident cancers among men with AIDS were KS $(469 ; 31.1 \%)$, NHL $(304 ; 20.1 \%)$, anal cancer $(63 ; 4.2 \%)$, colorectal cancer $(59 ; 3.9 \%)$ and lung cancer $(54,3.6 \%)$. In the general male population, the most frequent cancer sites were prostate $(23.4 \%)$, colon and rectum $(9.5 \%)$, lung $(7.2 \%)$, stomach $(6.5 \%)$ and skin non-melanoma (6.1\%) (data not shown).

In women with AIDS, CC $(114 ; 20.2 \%)$, NHL (96; $17.0 \%)$, breast cancer $(72 ; 12.8 \%)$, KS $(34 ; 6.0 \%)$ and colorectal cancer $(19 ; 3.4 \%)$ were the most incident cancers. In contrast, among women from the general population, breast $(25.6 \%)$, colon and rectum $(8.9 \%)$, 
Table 2. Socio-demographic characteristics of 2000 people with AIDS and cancer, according to gender. São Paulo, 1997-20I2.

\begin{tabular}{|c|c|c|c|c|c|c|}
\hline & \multicolumn{2}{|c|}{ Total } & \multicolumn{2}{|c|}{ Male } & \multicolumn{2}{|c|}{ Female } \\
\hline & $\mathrm{n}$ & $\%$ & $\mathrm{n}$ & $\%$ & $\mathrm{n}$ & $\%$ \\
\hline \multicolumn{7}{|l|}{ Race/ethnicity } \\
\hline White & IIII & 55.6 & 860 & 58.9 & 251 & 46.6 \\
\hline Black & 143 & 7.2 & 84 & 5.7 & 59 & 10.9 \\
\hline Asian & 14 & 0.7 & 10 & 0.7 & 4 & 0.7 \\
\hline Pardo $^{\mathrm{a}}$ & 255 & 12.8 & 159 & 10.9 & 96 & 17.8 \\
\hline Unknown & 477 & 23.9 & 348 & 23.8 & 129 & 23.9 \\
\hline \multicolumn{7}{|c|}{ Age at AIDS diagnosis (years) } \\
\hline $13-19$ & 16 & 0.8 & 9 & 0.6 & 7 & 1.3 \\
\hline $20-29$ & 348 & 17.4 & $24 I$ & 16.5 & 107 & 19.9 \\
\hline $30-39$ & 733 & 36.7 & 534 & 36.6 & 199 & 36.9 \\
\hline $40-49$ & 528 & 26.4 & 397 & 27.2 & $|3|$ & 24.3 \\
\hline $50-59$ & 277 & 13.9 & 210 & 14.4 & 67 & 12.4 \\
\hline $60-69$ & 82 & 4.1 & 55 & 3.8 & 27 & 5.0 \\
\hline$\geq 70$ & 16 & 0.8 & 15 & 1.0 & I & 0.2 \\
\hline \multicolumn{7}{|c|}{ Age at cancer diagnosis (years) } \\
\hline $13-19$ & 8 & 0.4 & 6 & 0.4 & 2 & 0.4 \\
\hline $20-29$ & 225 & 11.3 & 163 & 11.2 & 62 & 11.5 \\
\hline $30-39$ & 650 & 32.5 & 467 & 32.0 & 183 & 34.0 \\
\hline $40-49$ & 607 & 30.4 & 438 & 30.0 & 169 & 31.4 \\
\hline $50-59$ & 348 & 17.4 & 271 & 18.5 & 77 & 14.3 \\
\hline $60-69$ & 135 & 6.8 & 95 & 6.5 & 40 & 7.4 \\
\hline$\geq 70$ & 27 & 1.4 & 21 & 1.4 & 6 & I.I \\
\hline \multicolumn{7}{|l|}{ HIV exposure category } \\
\hline Homosexual men & 447 & 22.4 & 447 & 30.6 & NA & NA \\
\hline Bisexual & 179 & 9.0 & 179 & 12.3 & - & - \\
\hline Heterosexual & 674 & 33.7 & 313 & 21.4 & 361 & 67.0 \\
\hline Intravenous drug user & 145 & 7.3 & 105 & 7.2 & 40 & 7.4 \\
\hline Other & 10 & 0.5 & 4 & 0.3 & 6 & I.I \\
\hline Unknown & 545 & 27.3 & 413 & 28.3 & 132 & 24.5 \\
\hline Total & 2000 & 100 & |46 | & 100 & 539 & 100 \\
\hline
\end{tabular}

NA: not applicable.

${ }^{\text {a }}$ Pardo refers to multiracial persons of African ancestry.

thyroid $(7.5 \%)$, cervix $(5.2 \%)$ and skin non-melanoma $(5.2 \%)$ were the most frequent cancer sites (data not shown).

As for the trend analyses in men with AIDS, a statistically significant decline was seen in general for ADCs ( $\mathrm{APC}=-14.1 \% /$ year $)$, but also in particular for $\mathrm{KS}$ $(\mathrm{APC}=-16.2 \% /$ year $)$ and NHL $(\mathrm{APC}=-11.9 \% /$ year $)$. In contrast to this, all NADCs decreased (APC $=$ $-9.7 \%$ year) until the mid-2000s, when it started to increase ( $\mathrm{APC}=7.4 \% /$ year). Incidence of anal and lung cancer have significantly increased by 24.6 and $15.9 \%$, respectively, whereas colorectal cancer remained stable. In the general male population, NHL, colorectal, lung and anal cancers had significant declines in incidence of $-2.8,-1.3,-7.6,-5.9 \% / y e a r$, respectively (Figure 1(a) to (d)).

Among women with AIDS, a statistically significant decline was seen in general for ADCs $(\mathrm{APC}=-15.6 \%$ / year), and in particular for $\mathrm{KS}(\mathrm{APC}=-26.7 \% /$ year $)$, NHL $\quad(\mathrm{APC}=-15.8 \% /$ year $), \quad \mathrm{CC} \quad(\mathrm{APC}=-12.8 \%$ / year) and breast cancer $(\mathrm{APC}=-10.1 \% /$ year $)$ in particular. In contrast to this, the incidence of colorectal cancer remained stable. Additionally, also for all NADCs (APC $=-15.8 \% /$ year), the decline was significant. Declining trends in all cancers analysed were found for women from the general population. 
Table 3. Trends in 2074 cancer cases found among 2000 people with AIDS and cancer and people from general population, according to sex. São Paulo, 1997-2012.

\begin{tabular}{|c|c|c|c|c|c|c|c|c|}
\hline & \multicolumn{4}{|c|}{ Persons with AIDS } & \multicolumn{4}{|c|}{ General population } \\
\hline & $\mathrm{n}$ & APC & $95 \% \mathrm{Cl}$ & $\mathrm{P}$ & $\mathrm{n}$ & APC & $95 \% \mathrm{Cl}$ & $\mathrm{P}$ \\
\hline \multicolumn{9}{|l|}{ Male $^{\mathrm{a}}$} \\
\hline All AIDS-defining cancers & 773 & -14.1 & $-16.6 ;-11.6$ & $<0.01$ & NA & NA & NA & NA \\
\hline Kaposi sarcoma & 469 & -16.2 & $-18.8 ;-13.4$ & $<0.01$ & NA & NA & NA & NA \\
\hline Non-Hodgkin lymphoma & 304 & -11.9 & $-15.5 ;-8.2$ & $<0.01$ & 7719 & -2.8 & $-3.5 ;-2.1$ & $<0.01$ \\
\hline All non-AIDS-defining cancers $(1997-2005)^{b}$ & 361 & -9.7 & $-12.2 ;-7.1$ & $<0.01$ & NA & NA & NA & NA \\
\hline All non-AIDS-defining cancers (2005-20I2) & 376 & 7.4 & $3.6 ; 11.4$ & $<0.01$ & NA & NA & NA & NA \\
\hline Anal cancer ${ }^{c}$ & 63 & 24.6 & $16.0 ; 33.9$ & $<0.01$ & 616 & -5.9 & $-10.1 ;-1.5$ & $<0.01$ \\
\hline Colorectal cancer & 59 & -3.9 & $-11.5 ; 4.3$ & 0.30 & 22,565 & -1.3 & $-2.1 ;-0.5$ & $<0.01$ \\
\hline Lung cancer & 54 & 15.9 & $6.9 ; 25.7$ & $<0.01$ & 17,082 & -7.6 & $-8.3 ;-6.9$ & $<0.01$ \\
\hline \multicolumn{9}{|l|}{ Female $^{d}$} \\
\hline All AIDS-defining cancers & 244 & -15.6 & $-18.8 ;-12.3$ & $<0.01$ & NA & NA & NA & NA \\
\hline Cervical cancer & 114 & -12.8 & $-16.3 ;-9.2$ & $<0.01$ & 14,765 & -8.2 & $-9.1 ;-7.3$ & $<0.01$ \\
\hline Non-Hodgkin lymphoma & 96 & -15.8 & $-20.0 ;-11.4$ & $<0.01$ & 7220 & -2.4 & $-3.0 ;-1.7$ & $<0.01$ \\
\hline Kaposi sarcoma & 34 & -26.7 & $-34.7 ;-17.7$ & $<0.01$ & NA & NA & NA & NA \\
\hline All non-AIDS-defining cancers & 320 & -15.8 & $-20.0 ;-11.3$ & $<0.01$ & NA & NA & NA & NA \\
\hline Breast cancer & 72 & -10.1 & $-19.1 ;-0.2$ & $<0.01$ & 72,134 & -1.8 & $-2.5 ;-1.1$ & $<0.01$ \\
\hline Colorectal cancer & 19 & 1.9 & $-10.3 ; 15.8$ & 0.70 & 24,975 & -1.5 & $-2.3 ;-0.7$ & $<0.01$ \\
\hline
\end{tabular}

APC: annual per cent change; $\mathrm{Cl}$ : confidence interval; NA: not applicable.

${ }^{a}$ Cancer cases add up to 1510 in men with AIDS.

begment provided by Joinpoint.

'2002 onwards.

${ }^{\mathrm{d}}$ Cancer cases add up to 564 in the women with AIDS.

The analysis of crude rates stratified by age group revealed that the risk for all ADCs (KS, NHL and CC) increased with age (Figure 2(a) and (b)). Risk for all NADCs among persons with AIDS was 38.3-fold in men and 35.6-fold in women, when comparing the oldest (60-69 years) to the youngest age group (20-29 years).

\section{Discussion}

This is the first study in Brazil estimating the incidence of cancer in patients with AIDS at a population level. Our results reveal a high and changing cancer burden in this population, as found in similar studies conducted in North America and Europe, as well as a multicentre cohort study performed in Rio de Janeiro (Brazil) and Nashville (US). ${ }^{2,4,5,12,13}$

Although approximately half of cancers identified in our study were classified as ADCs, their incidences have dramatically declined in São Paulo, but remain at high rates when compared to the general population. Declining trends in ADCs have been documented in several studies, with one of the most probable contributors to this being the introduction of HAART in 1996. ${ }^{2,5}$ Treatment with HAART, if timely, alters the course of HIV infection by preventing or reversing profound immunosuppression, and thereby, decreasing susceptibility of developing AIDS-defining illnesses, including ADCs. ${ }^{14,15}$ Despite efforts to scale up HIV testing and early diagnosis, late entries to HIV care are still very frequent worldwide and could prevent further reduction in ADCs burden. ${ }^{16,17}$ A study conducted in Brazil revealed that between 2003 and 2006, 43.6\% of persons aged 15 and older diagnosed with AIDS entered HIV care late, either having CD4+ cell counts $\leq 200$ cells $/ \mathrm{mm}^{3}$, an AIDS-defining illness at the initial examination or having died within the first 20 days of entry. ${ }^{18}$ In these cases, delayed introduction of HAART could be less effective in improving the immune system and its ability to control oncogenic viruses, such as Epstein-Barr virus (risk factor for NHL) and human herpes virus 8 (associated with KS), increasing the overall risk for ADCs.

On the other hand, since 2013, the Brazilian Ministry of Health encourages the immediate initiation of antiretroviral therapy among all individuals diagnosed with HIV infection, regardless of CD4+ cell counts. ${ }^{19}$ This measure could lead to further declines in ADCs, by preventing persons diagnosed with HIV only from developing AIDS and its defining illnesses.

Steep reduction $(\mathrm{APC}=-15.8 \%$ in women; $-11.9 \%$ in men) in NHL in the AIDS population could have 


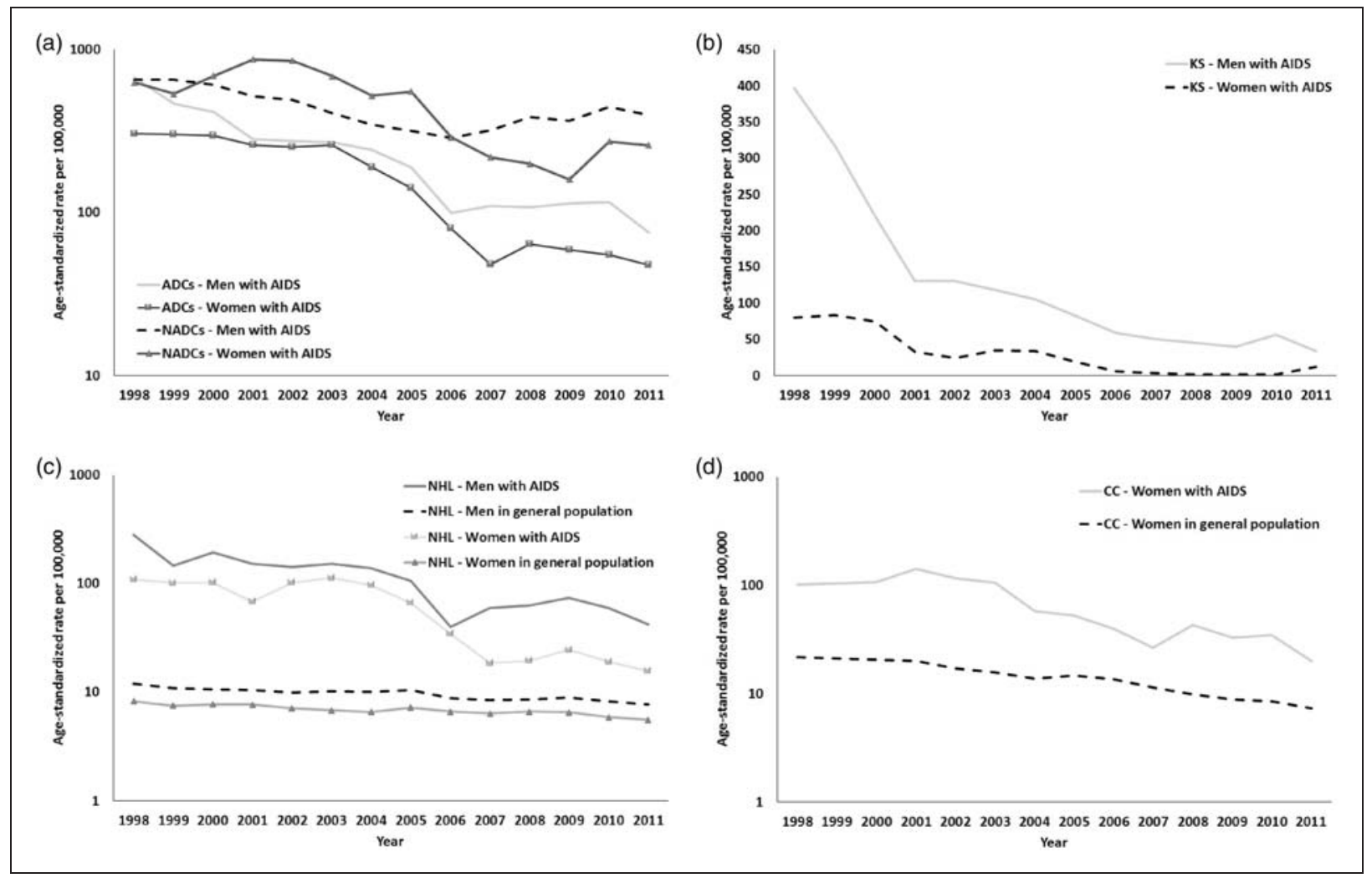

Figure I. (a) Age standardized incidence rates of AIDS-defining and non-AIDS-defining cancers in the AIDS population according to gender. São Paulo, 1997-2012. Rates are presented based on three-year moving average and displayed on a logarithmic scale. (b) Age standardized incidence rates of Kaposi's sarcoma in the AIDS population according to gender. São Paulo, 1997-20I2. Rates are presented based on three-year moving average. (c) Age standardized incidence rates of non-Hodgkin lymphoma in the AIDS population and in the general population according to gender. São Paulo, 1997-2012. Rates are presented based on three-year moving average and displayed on a logarithmic scale. (d) Age standardized incidence rates of cervical cancer in the AIDS population and in the general population. São Paulo, 1997-2012. Rates are presented based on three-year moving average and displayed on a logarithmic scale.

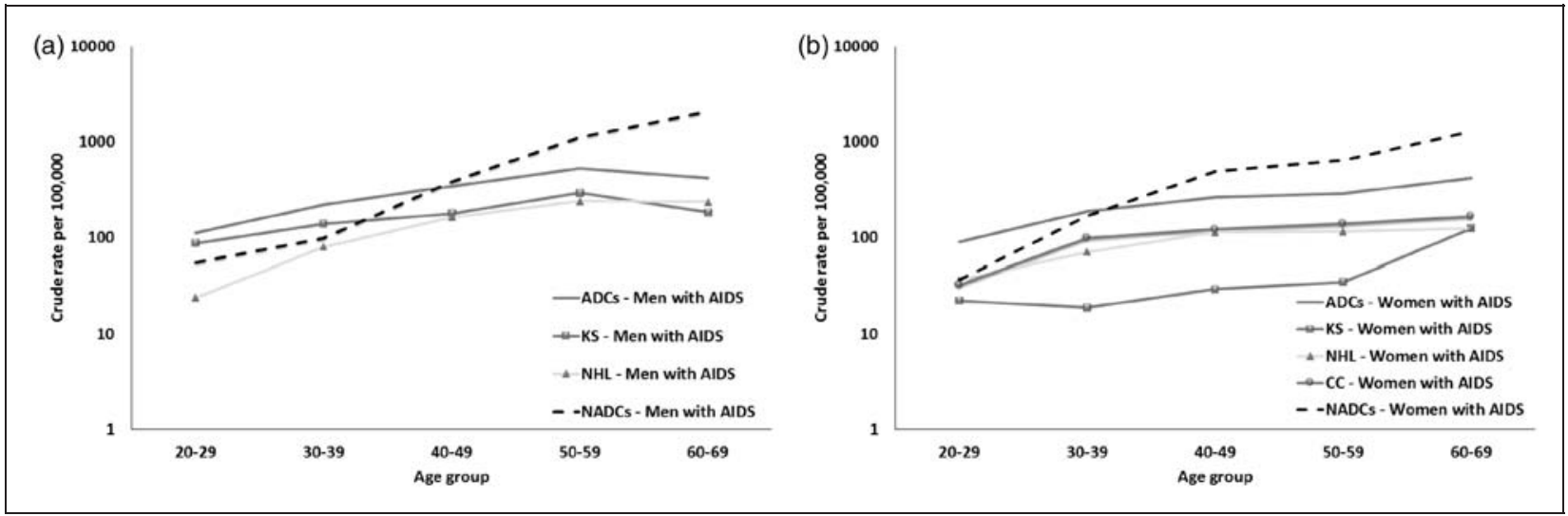

Figure 2. (a) Crude incidence rates for AIDS-defining cancers, non-AIDS-defining cancers, Kaposi's sarcoma and non-Hodgkin lymphoma in men with AIDS according to age group. Sao Paulo, 1997-20I2. Rates are displayed on a logarithmic scale. (b) Crude incidence rates for AIDS-defining cancers, non-AIDS-defining cancers, Kaposi's sarcoma, non-Hodgkin lymphoma and cervical cancer in women with AIDS according to age group. Sao Paulo, 1997-2012. Rates are displayed on a logarithmic scale. 
contributed to declining trends at the general population level $(\mathrm{APC}=-2.4 \%$ in women; $-2.8 \%$ in men), as they account for $4 \%$ of all cases. Similar declining patterns for CC were identified in women with AIDS and women from the general population. In both cases, the propagation of Pap smear screening may have contributed to this epidemiological pattern as the test can identify cervical lesions before they evolve to CC. In São Paulo, over $90 \%$ of female inhabitants belonging to the screening target group reported to have had at least one Pap smear in the last three years. ${ }^{20}$

Conversely, NADCs have become progressively crucial over the years. In both men and women, incidence of NADCs surpassed ADCs in the mid-2000s, but in men, the incidence has been particularly increasing since 2005, driven by lung and anal cancers. Other NADCs, such as female breast and colorectal cancers in the AIDS population follow the pattern of the general population. In São Paulo, coverage of the breast cancer screening programme is about $80 \%{ }^{20}$

The increasing trend in lung cancer among men is not surprising. According to the Brazilian Ministry of Health, the prevalence of smoking among PLWHA ranges from 50 to $70 \%,{ }^{19}$ which is considerably higher than that of the general population $(14.9 \%$ in 2013 in São Paulo). ${ }^{20}$ Recent data from the US revealed that lung cancer has decreased more rapidly in PLWHA than in the general population, though the authors believe that this might result from a faster decline in smoking prevalence in the first group. ${ }^{2}$ In São Paulo there are no data suggesting changes in smoking prevalence in this population. In line with our results, lung cancer in PLWHA in Italy has increased in the post-HAART era when compared to the pre-HAART era. ${ }^{5}$ Previous studies have shown that higher incidence of lung cancer in this population is mainly attributable to tobacco smoking rather than other cofactors. $^{21}$ There is an ongoing debate on the effectiveness of screening for lung cancer, and until there is enough evidence to adopt it, management of this malignancy must focus on strategies to promote tobacco cessation.

As for anal cancer in the male population with AIDS, there is a clear increasing trend since 2002, which is contrary to the drop observed in the general population. Similar results have been reported in Italy and the US, though in the US increasing trends in anal cancer in the AIDS population have been identified as driving the upward trend in the general population. ${ }^{2,5}$ Anal cancer has been strongly linked to persistent HPV infection and tobacco smoking, ${ }^{22}$ and the risk among PLWHA is as high as 37 -fold when compared to the general population. ${ }^{23} \mathrm{~A}$ multicentre study in Brazil of 445 HIV-positive men, found a $65.6 \%$ prevalence of HPV DNA in anal swabs, with
$40.7 \%$ detected as oncogenic HPV strains. ${ }^{24}$ In an effort towards early detection of anal cancer and its precursor lesions in PLWHA, the Brazilian Ministry of Health has recommended since 2013 annual anal Pap smears for patients who have receptive anal intercourse, HPV infection history, or abnormal vulvar or cervical histology. ${ }^{19}$ This strategy could lead to changes in anal cancer burden in the high-risk population in the future. ${ }^{25}$

Our findings are closer to that of industrialized countries, probably due to two aspects: the characteristics of the AIDS epidemic and the access to antiretroviral therapy. In São Paulo, AIDS is still more prevalent in men, with homosexual exposure to HIV representing an important mode of transmission. However, male-to-female ratio of AIDS cases has dramatically fallen from $26: 1$ in 1985 to $2: 1$ in $2011 .^{26}$ In the US and Western European countries, the populations of PLWHA have similar features, whereas in sub-Saharan Africa, women are disproportionally more affected by AIDS and heterosexual infection is predominant. ${ }^{27}$ Concerning antiretroviral therapy, provided in Brazil since 1996, treatment is free of cost to all patients in need. Thus, regardless of a patient's economic condition, treatment is universal. ${ }^{28}$

The analysis of crude rates by age groups highlights that as patients age the risk for cancer increases, but the risk is more pronounced for NADCs. Incidence of NADCs peaks at older ages, a pattern observed for most cancers in the general population. Polesel et al., ${ }^{5}$ when assessing NADCs in PLWHA in Italy, concluded that the strong changes in crude rates were driven by the ageing of the AIDS population. ${ }^{5}$

As for limitations, this study is restricted to the AIDS population and does not examine HIV-only patients. Even though the city of São Paulo occasionally provided notices regarding HIV infection, notification has only recently become mandatory (in June 2014). Thus, data for HIV-only cases for the study period are not precise and was therefore not analysed. Information on clinical data, including CD4+ cell count, viral load and antiretroviral therapy was not assessed because it is not routinely collected by the AIDS registry (SINAN).

The shorter coverage period of the PBCR-SP has limited our analysis to the post-HAART era. It would have been valuable to understand the risk for cancer in this population before HAART became fully available.

Three main sources of cancer underestimation may have occurred in our study. First, this study relies on probabilistic record linkage itself. This method is not error free and might have failed in the identification of some of those PLWHA who had cancer in the study period. To minimize this issue and improve our data matching sensitivity, a multi-step process was carried 
out and clerical review was employed. Even so, some degree of underestimation may have occurred. Nevertheless, this strategy has also been employed to estimate cancer incidence in PLWHA in other countries and is the primary source of population-based data.

A second factor that could result in cancer underestimation is outmigration. Residents of São Paulo who were diagnosed with AIDS and outmigrated later could not be captured by our database linkage. There are no data on the percentage of outmigration among AIDS patients, but available information from a report assessing incident cancer cases registered in São Paulo revealed that $4 \%$ of deaths were registered outside the municipality (outmigration). ${ }^{29}$ If one assumes that the percentage of AIDS cases that moved to other municipalities is similar and that not all of them would develop cancer, then outmigration would not greatly interfere with our findings.

Lastly, PLWHA who are unaware of their status may have been misclassified in our study, and therefore failed to contribute to the cancer burden in persons with AIDS. Nevertheless, this is to be expected in studies, which are based on passive case finding.

Despite the aforementioned constraints, the present study provides valuable population-based information from a developing country. The current body of knowledge is composed mainly of research conducted in developed countries with this study providing aggregated data from a developing country known for its particular plan to fight AIDS. Our findings highlight a marked decrease in ADCs for both genders and a recent increase in NADCs among men, mainly driven by lung and anal cancers. Stratification by gender was important to identify different patterns in cancer trends. This suggests that exposure to risk factors for cancer, such as smoking, varies according to gender and has to be accounted for in explanations of gender differences. In addition, women tend to seek health care more frequently than men do and this might have affected the risk of cancer. ${ }^{30}$

Risk for cancer in persons with AIDS increases dramatically as they age, with a similar pattern seen in the general population. Because PLWHA are living longer and reaching older ages due to advances in disease treatment, cancer in this population will remain an important issue to be addressed. Strategies to promote lifestyle changes to reduce or eliminate modifiable risk factors such as tobacco smoking, as well as screening and early cancer detection are key points for the management of cancer in PLWHA.

\section{Declaration of conflicting interests}

The authors declared no potential conflicts of interest with respect to the research, authorship, and/or publication of this article.

\section{Funding}

The authors disclosed receipt of the following financial support for the research, authorship, and/or publication of this article: Conselho Nacional de Desenvolvimento Cientifico e Tecnológico-CNPq (grant number: 141439/2013-0). The Center for International Health is funded by the German Ministry for Economic Cooperation and Development through the German Academic Exchange Service (DAAD) and the Higher Education Excellence in Development Cooperation (Exceed).

\section{References}

1. Engels EA, Biggar RJ, Hall HI, et al. Cancer risk in people infected with human immunodeficiency virus in the United States. Int J Cancer 2008; 123: 187-194.

2. Robbins HA, Shiels MS, Pfeiffer RM, et al. Epidemiologic contributions to recent cancer trends among HIV-infected people in the United States. AIDS 2014; 28: 881-890.

3. Robbins HA, Pfeiffer RM, Shiels MS, et al. Excess cancers among HIV-infected people in the United States. J Natl Cancer Inst 2015; 107: dju503.

4. Galceran J, Marcos-Gragera R, Soler M, et al. Cancer incidence in AIDS patients in Catalonia, Spain. Eur $J$ Cancer 2007; 43: 1085-1091.

5. Polesel J, Franceschi S, Suligoi B, et al. Cancer incidence in people with AIDS in Italy. Int J Cancer 2010; 127: 1437-1445.

6. Berkman A, Garcia J, Muñoz-Laboy M, et al. A critical analysis of the Brazilian response to HIV/AIDS: lessons learned for controlling and mitigating the epidemic in developing countries. Am J Public Health 2005; 95: 1162-1172.

7. Brasil. Ministério da Saúde. Secretaria de Vigilância em Saúde. Departamento de DST AIDS e Hepatites Virais, http://www2.aids.gov.br/final/dados/dados_aids.asp (accessed August 2016).

8. Vigilância Epidemiológica de DST/AIDS. Secretaria Municipal de Saúde, São Paulo, http://tabnet.saude.prefeitura.sp.gov.br/cgi/deftohtm3.exe?secretarias/saude/ TABNET/AIDS/AIDSAD.def (accessed August 2016).

9. Brasil. Ministério da Saúde. Secretaria de Vigilância em Saúde. Departamento de DST AIDS e Hepatites Virais. Critérios de definição de casos de AIDS em adultos e crianças. Brasilia: Ministério da Saúde, 2004.

10. Instituto Brasileiro de Geografia, http://cidades.ibge.gov. br $/$ xtras/perfil.php?lang $=\& \operatorname{codmun}=355030 \&$ search $=$ sao-paulo|sao-paulo (accessed May 2016).

11. Doll WRS and Waterhouse J. Cancer incidence in five continents: a technical report. Berlin: Springer-Verlag, 1966.

12. Clifford GM, Polesel J, Rickenbach M, et al. Cancer risk in the Swiss HIV Cohort Study: associations with immunodeficiency, smoking, and highly active antiretroviral therapy. J Natl Cancer Inst 2005; 97: 425-432.

13. Castilho JL, Luz PM, Shepherd BE, et al. HIV and cancer: a comparative retrospective study of Brazilian and U.S. clinical cohorts. Infect Agent Cancer 2015; 10: 4. 
14. Rubinstein PG, Aboulafia DM and Zloza A Malignancies in HIV/AIDS: from epidemiology to therapeutic challenges. AIDS 2014; 28: 453-465.

15. Cobucci RN, Lima PH, de Souza PC, et al. Assessing the impact of HAART on the incidence of defining and non-defining AIDS cancers among patients with HIV/ AIDS: a systematic review. J Infect Public Health 2015; 8: $1-10$

16. Althoff K, Gange S, Klein M, et al. Late presentation for human immunodeficiency virus care in the United States and Canada. Clin Infect Dis 2010; 50: 1512-1520.

17. Dickson N, McAllister S, Sharples K, et al. Late presentation of HIV infection among adults in New Zealand: 2005-2010. HIV Med 2011; 13: 182-189.

18. Grangeiro A, Escuder M, Menezes PR, et al. Late entry into HIV care: estimated impact on AIDS mortality rates in Brazil, 2003-2006. PLoS One 2011; 6: 14585.

19. Brasil. Ministério da Saúde. Secretaria de Vigilância em Saúde. Departamento de DST AIDS e Hepatites Virais. Clinical protocol and therapeutic guidelines for integral care to people with sexually transmitted infections. Brasilia: Ministério da Saúde, 2015.

20. Brasil. Ministério da Saúde. Secretaria de Vigilância em Saúde. Secretaria de Gestão Estratégica e Participativa. Vigitel 2013: Vigilância de fatores de risco e proteção para doenças crônicas por inquérito telefônico. Brasília: Ministério da Saúde, 2014.

21. Clifford GM, Lise M, Franceschi S, et al. Lung cancer in the Swiss HIV Cohort Study: role of smoking, immunodeficiency and pulmonary infection. Br J Cancer 2012; 106: $447-452$.
22. Daling JR, Madeleine MM, Johnson LG, et al. Human papillomavirus, smoking, and sexual practices in the etiology of anal cancer. Cancer 2004; 101: 270-280.

23. Coghill AE, Shiels MS, Rycroft RK, et al. Rectal squamous cell carcinoma in immunosuppressed populations: is this a distinct entity from anal cancer? AIDS 2015; 30: $105-112$.

24. Guimaraes MD, Grinsztejn B, Melo V, et al. Anal HPV prevalence and associated factors among HIVseropositive men under antiretroviral treatment in Brazil. J Acquir Immune Defic Syndr 2011; 57: S217-S224.

25. Nathan M, Singh N, Garrett N, et al. Performance of anal cytology in a clinical setting when measured against histology and high-resolution anoscopy findings. AIDS 2010; 24: 373-379.

26. São Paulo. Coordenadora de Vigilância em Saúde. Secretaria Municipal de Saúde. Boletim Epidemiológico de Aids, HIV/DST e Hepatites B e C do Município de São Paulo. São Paulo: SMS, 2011.

27. Ramjee $G$ and Daniels B. Women and HIV in subSaharan Africa. AIDS Res Ther 2013; 10: 30.

28. Antunes JL, Waldman EA and Borrell C. Is it possible to reduce AIDS deaths without reinforcing socioeconomic inequalities in health? Int J Epidemiol 2005; 34: 586-592.

29. Taniguchi $M$ and Latorre MRDO. Relacionamento probabilístico entre as bases de dados do registro de câncer de São Paulo e do sistema de informacões de mortalidade municipal. São Paulo: Universidade de São Paulo, 2006.

30. Baker P, Dworkin SL, Tong S, et al. The men's health gap: men must be included in the global health equity agenda. Bull World Health Organ 2014; 92: 618-620. 